\title{
Molecular imaging of inflammation and intraplaque vasa vasorum: A step forward to identification of vulnerable plaques?
}

\author{
Gerrit L. ten Kate, $M D,{ }^{a, b}$ Eric J. G. Sijbrands, $M D, P h D,{ }^{a}$ Roelf Valkema, $M D$, \\ $\mathrm{PhD},{ }^{\mathrm{c}}$ Folkert J. ten Cate, $\mathrm{MD}, \mathrm{PhD},{ }^{\mathrm{b}}$ Steven B. Feinstein, $\mathrm{MD},{ }^{\mathrm{d}}$ \\ Antonius F. W. van der Steen, PhD, ${ }^{e}$ Mat J. A. P. Daemen, MD, PhD, ${ }^{f}$ \\ and Arend F. L. Schinkel, MD, PhD ${ }^{\mathrm{a}, \mathrm{b}}$
}

Current developments in cardiovascular biology and imaging enable the noninvasive molecular evaluation of atherosclerotic vascular disease. Intraplaque neovascularization sprouting from the adventitial vasa vasorum has been identified as an independent predictor of intraplaque hemorrhage and plaque rupture. These intraplaque vasa vasorum result from angiogenesis, most likely under influence of hypoxic and inflammatory stimuli. Several molecular imaging techniques are currently available. Most experience has been obtained with molecular imaging using positron emission tomography and single photon emission computed tomography. Recently, the development of targeted contrast agents has allowed molecular imaging with magnetic resonance imaging, ultrasound and computed tomography. The present review discusses the use of these molecular imaging techniques to identify inflammation and intraplaque vasa vasorum to identify vulnerable atherosclerotic plaques at risk of rupture and thrombosis. The available literature on molecular imaging techniques and molecular targets associated with inflammation and angiogenesis is discussed, and the clinical applications of molecular cardiovascular imaging and the use of molecular techniques for local drug delivery are addressed.

Key Words: Atherosclerosis $\cdot$ angiogenesis $\bullet$ inflammation $\cdot$ molecular imaging • vasa vasorum $\cdot$ vulnerable atherosclerotic plaque

\section{INTRODUCTION}

The combination of cardiovascular and molecular imaging is rapidly evolving. Current developments in

\footnotetext{
From the Division of Pharmacology, ${ }^{\mathrm{a}}$ Vascular and Metabolic Diseases, Department of Internal Medicine, Erasmus Medical Center, Rotterdam, The Netherlands; Department of Cardiology, ${ }^{\mathrm{b}}$ Thoraxcenter, Erasmus Medical Center, Rotterdam, The Netherlands; Department of Nuclear Medicine, ${ }^{c}$ Department of Internal Medicine, Erasmus Medical Center, Rotterdam, The Netherlands; Section of Cardiology, ${ }^{\mathrm{d}}$ Department of Internal Medicine, Rush University Medical Center, Chicago, IL; Department of Biomedical Engineering, ${ }^{\mathrm{e}}$ Thoraxcenter, Erasmus Medical Center, Rotterdam, The Netherlands; and Department of Pathology, ${ }^{\mathrm{f}}$ Cardiovascular Research Institute Maastricht, Maastricht University Medical Center, Maastricht, The Netherlands.

Reprint requests: Arend F. L. Schinkel, MD, PhD, Department of Cardiology, Thoraxcenter, Erasmus Medical Center, Room Ba304, 's-Gravendijkwal 230, 3015 CE Rotterdam, The Netherlands; a.schinkel@erasmusmc.nl.

J Nucl Cardiol 2010;17:897-912.

$1071-3581 / \$ 34.00$

Copyright (c) 2010 The Author(s). This article is published with open access at Springerlink.com

doi:10.1007/s12350-010-9263-x
}

cardiovascular biology and imaging provide noninvasive molecular evaluation of atherosclerotic vascular disease, aiding in the detection of vulnerable plaques, at risk of rupture and subsequent thrombosis. ${ }^{1,2}$ Essential to the successful development of molecular imaging is the search for a safe, noninvasive imaging technique capable of early detection of the key pathological processes of cardiovascular disease, identifying vulnerable plaques and thus patients at an increased risk of cardiovascular events. $^{3}$

A number of pathophysiological mechanisms are thought to be involved in the progression of an atherosclerotic lesion into a vulnerable plaque. ${ }^{4}$ Intraplaque neovascularization of the vasa vasorum has gained interest as a preceding or concomitant factor in the development, progression, and instability of atherosclerotic plaques..$^{5-7}$ The intraplaque vasa vasorum are microvessels that sprout from the adventitial vasa vasorum, most likely under influence of hypoxic and inflammatory stimuli. ${ }^{8-12}$ The presence of intraplaque vasa vasorum has been identified as an independent predictor of intraplaque hemorrhage and plaque 
rupture. ${ }^{13,14}$ The intraplaque vasa vasorum are therefore increasingly investigated as a marker for the noninvasive identification of vulnerable plaques.

In the present review, the noninvasive molecular imaging of vasa vasorum neovascularization in the atherosclerotic plaque is discussed. First, an overview of the characteristics of vulnerable plaques and the role of inflammation and angiogenesis in vasa vasorum neovascularization is provided. Subsequently, the available literature on molecular imaging techniques and molecular targets associated with inflammation and angiogenesis is discussed. Finally, local drug delivery and the clinical application of molecular imaging in early detection of cardiovascular disease, evaluation of treatment effects, and use in drug development are addressed.

\section{PATHOPHYSIOLOGY OF THE VULNERABLE PLAQUE}

Traditionally, the burden of atherosclerotic disease was estimated from the percentage of stenosis detected by angiography. However, it has become apparent that plaque rupture and consequent cardiovascular events are dependent on the plaque composition rather than stenosis. Analyses of culprit lesions demonstrated that plaques vulnerable to rupture are characterized by active inflammation, a large lipid core with a thin fibrous cap, positive remodeling, intraplaque hemorrhage, and intraplaque neovascularization of the vasa vasorum. ${ }^{4}$

\section{Inflammation}

Inflammation is one of the hallmarks of plaque vulnerability. Macrophages are the most prevalent inflammatory cell in the atherosclerotic plaque and play a major role in the pathophysiology of plaque vulnerability. ${ }^{4,15,16}$ Macrophages secrete proteolytic enzymes, which degrade the extracellular matrix weakening the fibrotic cap structure and ultimately leading to plaque rupture. In addition, macrophages may secrete proangiogenic factors that stimulate the formation of vasa vasorum in atherosclerotic lesions. ${ }^{6,9,17}$ The vasa vasorum may serve as an important port of entry for additional inflammatory cells into the plaque. ${ }^{18,19}$

\section{Vasa Vasorum Neovascularization}

The vasa vasorum are functional end arteries, physiologically present in the adventitia of large arteries (vessels with a wall thickness $>0.5 \mathrm{~mm}$ ). The vasa vasorum provide nutrients to parts of the vessel wall that are too distant from the lumen for diffusion. $6,12,20$ Interruption of the adventitial vasa vasorum results in media necrosis, showing they are critical for the nourishment of the media. ${ }^{21-23}$

In the pathology of atherosclerosis dual, apparently contradictory roles for the vasa vasorum have been proposed. ${ }^{24}$ Vessel wall areas with low adventitial vasa vasorum density have been identified as preferred locations for the initiation of plaque formation, while the progression to advanced, symptomatic plaques is associated with a high intraplaque vasa vasorum density. ${ }^{10,11,25,26}$

The vasa vasorum are unevenly distributed along the vessel wall. It has been hypothesized that areas of low vasa vasorum density have less efflux of lipoproteins and are prone to inflammation. The influx of monocytes and subsequent differentiation into macrophages increase the metabolic demand in the vessel wall, while the supporting microvasculature may be insufficient. A relative hypoxic state and increased oxidative stress may occur, which may be the trigger for the formation of an atherosclerotic plaque. This hypothesis has been supported by the presence of hypoxic and inflammatory factors as hypoxia-inducible factor- $1 \alpha$ (HIF- $1 \alpha)$, nuclear transcription factor-kappa $\mathrm{B}$, tumor necrosis factor- $\alpha$ and interleukin- 6 , and an increased number of superoxide anions in regions with low vasa vasorum density. ${ }^{11,25,27-29}$

The increased density of vasa vasorum in advanced and symptomatic plaques is the result of microvessels sprouting from the existing adventitial vasa vasorum network by the process of angiogenesis. The initiation of angiogenesis is thought to be a physiological response to the inflammatory and hypoxic state of the vessel wall. The intraplaque vasa vasorum are formed to meet the increased metabolic demands of the developing atherosclerotic plaque. However, due to their poor structural integrity the intraplaque vasa vasorum may serve a pathologic role. ${ }^{10,18,25,26,30}$ They are immature, thinwalled vessels with increased size and even absence of the endothelial gap junctions (Figure 1). This may result in the extravasation of lipids, inflammatory cells and red blood cells and risks the collapse of the microvessels, contributing to progression into more advanced plaques. In humans over $80 \%$ of the intraplaque vasa vasorum are thin-walled and prone to leakage and rupture. ${ }^{31,32}$ Plaques with a high vasa vasorum density are consequently at an increased risk of intraplaque hemorrhage and plaque rupture. ${ }^{7,25}$

Whether the initiation of angiogenesis is an early or late process in the formation of the atherosclerotic plaques is still debated. Moreover, the key factors initiating angiogenesis in the atherosclerotic plaque are still largely unknown. ${ }^{25,33}$ An increase in vasa vasorum density has been shown to precede intimal thickening and even endothelial dysfunction. The latter is 


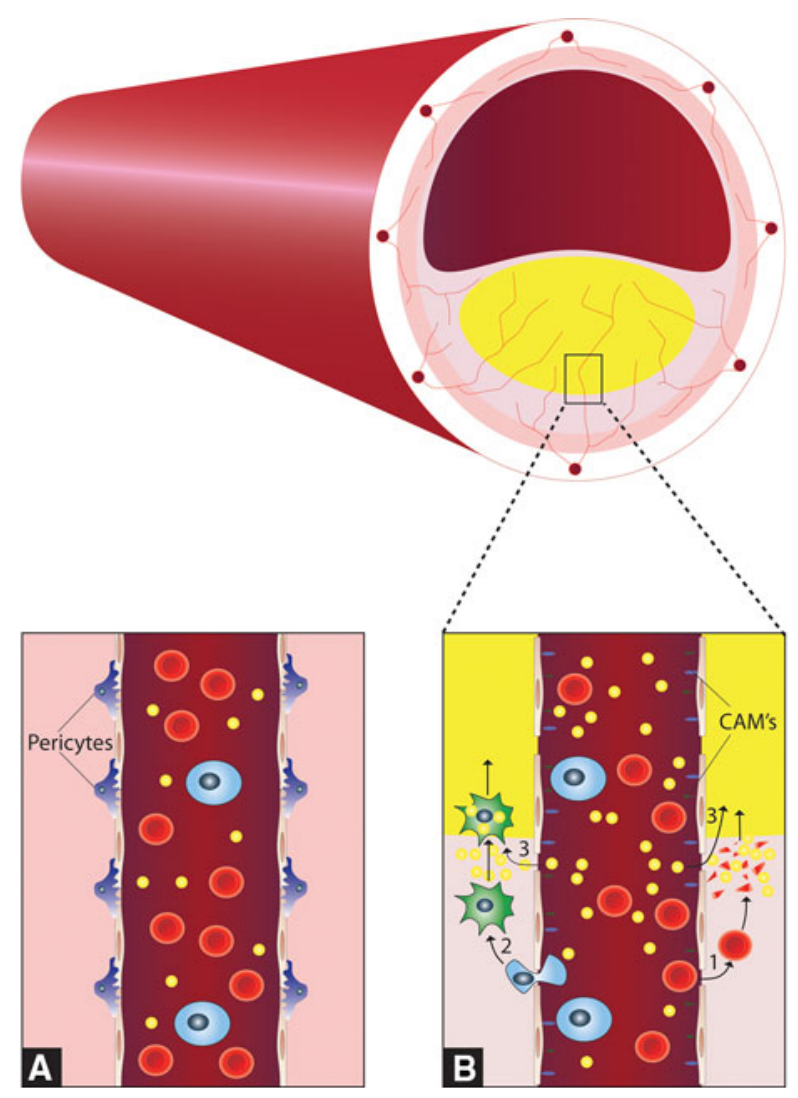

Figure 1. Schematic cross section of an atherosclerotic vessel with a large plaque, lipid core, and intraplaque vasa vasorum sprouting from the adventitial vasa vasorum network. Panel A shows the normal structure of the vasa vasorum with tight gap junctions. Panel B shows newly formed vasa vasorum with increased endothelial gap junctions, pericyte loss and expression of cellular adhesion molecules, the extravasation of erythrocytes ${ }^{1}$ and their consequent destruction, the adhesion and extravasation of monocytes ${ }^{2}$ and their subsequent transformation to macrophages and resultant foam cells and the direct extravasation of lipids. ${ }^{3}$ These factors cause growth of the lipid core of the atherosclerotic plaque.

traditionally thought of as one of the earliest changes in plaque development. ${ }^{34-36}$ Further studies are needed to elucidate the temporal relation and molecular regulation of angiogenesis in plaque formation.

\section{MOLECULAR IMAGING}

The recent years have seen a flight in both noninvasive (Table 1) and catheter-based molecular cardiovascular imaging techniques. ${ }^{37,38}$ Many of the developments have come from the field of cancer imaging, where molecular imaging by positron emission tomography (PET) and single photon emission computed tomography (SPECT) is readily used in clinical practice. Magnetic resonance imaging (MRI), ultrasound, and computed tomography (CT) are used in clinical practice for the visualization of anatomical structures, without necessarily visualizing biological processes. The development of targeted contrast agents has created a possibility for molecular imaging with these imaging techniques.

Molecular contrast agents generally consist of a ligand and a contrast element. The ligand is a molecule, for example an antibody, antibody fragment, peptide, or oligosaccharide, with a specific binding capacity to a molecular target. Its function is to retain the contrast element at the site of interest. The attached contrast element is specific to the imaging modality used, for example a radionuclide tracer for PET and SPECT, iodine for CT, gadolinium for MRI, or microbubbles for ultrasound. The contrast element can either be attached directly to the ligand, or via a carrier vehicle, such as a micelle, nanoparticle, or microbubble. In practice, multiple functions can be incorporated in one element. ${ }^{39}$

Both PET and SPECT imaging are used in conjunction with an intravenously administrated radionuclide tracer. To create an image PET and SPECT are dependent on the physical signal, either a positron or a photon, emitted by the tracer. This results in a high sensitivity for the detection of radionuclide tracers. PET and SPECT are able to accurately detect the tracer in very low concentrations $(<\mathrm{pg} / \mathrm{mL}){ }^{40}$ However, these imaging modalities lack anatomical detail and resolution, with PET reaching a maximum resolution of approximately $5 \mathrm{~mm}$ (two to three times better than SPECT). ${ }^{38}$ The use of radionuclide tracers is associated with ionizing radiation, and this potentially limits the clinical application. Much effort has been directed toward reducing the radiation dose and the effective dose equivalent (approximately $370 \mathrm{MBq}, 6.23 \mathrm{mSv}$ ) and organ doses are now comparable or lower than the radiation dose used in CT examinations, depending on the $\mathrm{CT}$ acquisition protocol. ${ }^{41}$ With modern equipment even lower activities of the tracer are required and a safe total radiation dose can be achieved.

For molecular imaging, MRI can be used in conjunction with either gadolinium or super paramagnetic iron oxide compounds (SPIO) that influence the magnetic resonance signal, resulting in an increase in $\mathrm{T} 1$ or a decrease in T2 signal, respectively. ${ }^{42}$ The predominantly used clinical MRI systems use a 1.5 -T field strength and are capable of reaching submillimeter resolutions. MRI avoids the use of ionizing radiation. However, gadolinium has been associated with nephrogenic systemic fibrosis in patients with reduced renal function. ${ }^{43,44}$

Ultrasound molecular contrast agents consist of microbubbles (1-5 $\mu \mathrm{m}$ diameter) stabilized by a lipid or 
protein shell. The microbubbles are an obligatory intravascular contrast agent, and the presence of microbubbles in an atherosclerotic plaque indicates the presence of intraplaque vasa vasorum. Ultrasound uniquely combines a submillimeter resolution and the capability to detect individual microbubbles, making contrast-enhanced ultrasound capable of identifying individual vasa vasorum in the vessel wall. However, the limited penetration depth restricts ultrasound to the investigation of the superficial vasculature. ${ }^{45-47}$ Ultrasound contrast agents have been used in echocardiography for decades and have been proven safe in large multicenter studies. ${ }^{48}$

Recently, the first molecular contrast agents have been developed for CT. ${ }^{40}$ Molecular CT imaging uses iodinated nanoparticles that increase the X-ray absorption at the targeted location. The high speed whole body scanning capability of multislice CT allows accurate visualization of atherosclerotic plaques in the coronary arteries. $^{40,49}$ The use of multislice CT for molecular imaging of the coronary arteries has not yet been investigated. The use of ionizing radiation potentially limits the use of CT, though the radiation dose in cardiovascular CT has substantially been reduced in recent years by the introduction of prospective ECG gating. ${ }^{50}$ The use of iodine contrast agents CT risks the development of a contrast-induced nephropathy, limiting its use in patients with decreased renal function. ${ }^{51}$

\section{MOLECULAR TARGETS}

The search for a safe, noninvasive imaging technique capable of early detection of atherosclerosis and risk stratification of patients with cardiovascular disease has resulted in the identification of various target-ligand combinations that are associated with plaque vulnerability. Angiogenesis and inflammation are closely related pathophysiological processes which are involved in both early plaque development and plaque vulnerability in patients with more advanced atherosclerosis. Tables 2 and 3 provide an overview of the molecular targets investigated for the identification of inflammatory and angiogenic processes respectively.

\section{INFLAMMATION-RELATED MOLECULAR TARGETS}

\section{Macrophages}

Inflamed plaques show an increased metabolism as a result of the increase in inflammatory cells, predominantly macrophages. The increased metabolism can be visualized by ${ }^{18}$ F-fluorodeoxyglucose (FDG) PET (Figure 2). FDG is a radionuclide-labeled glucose 


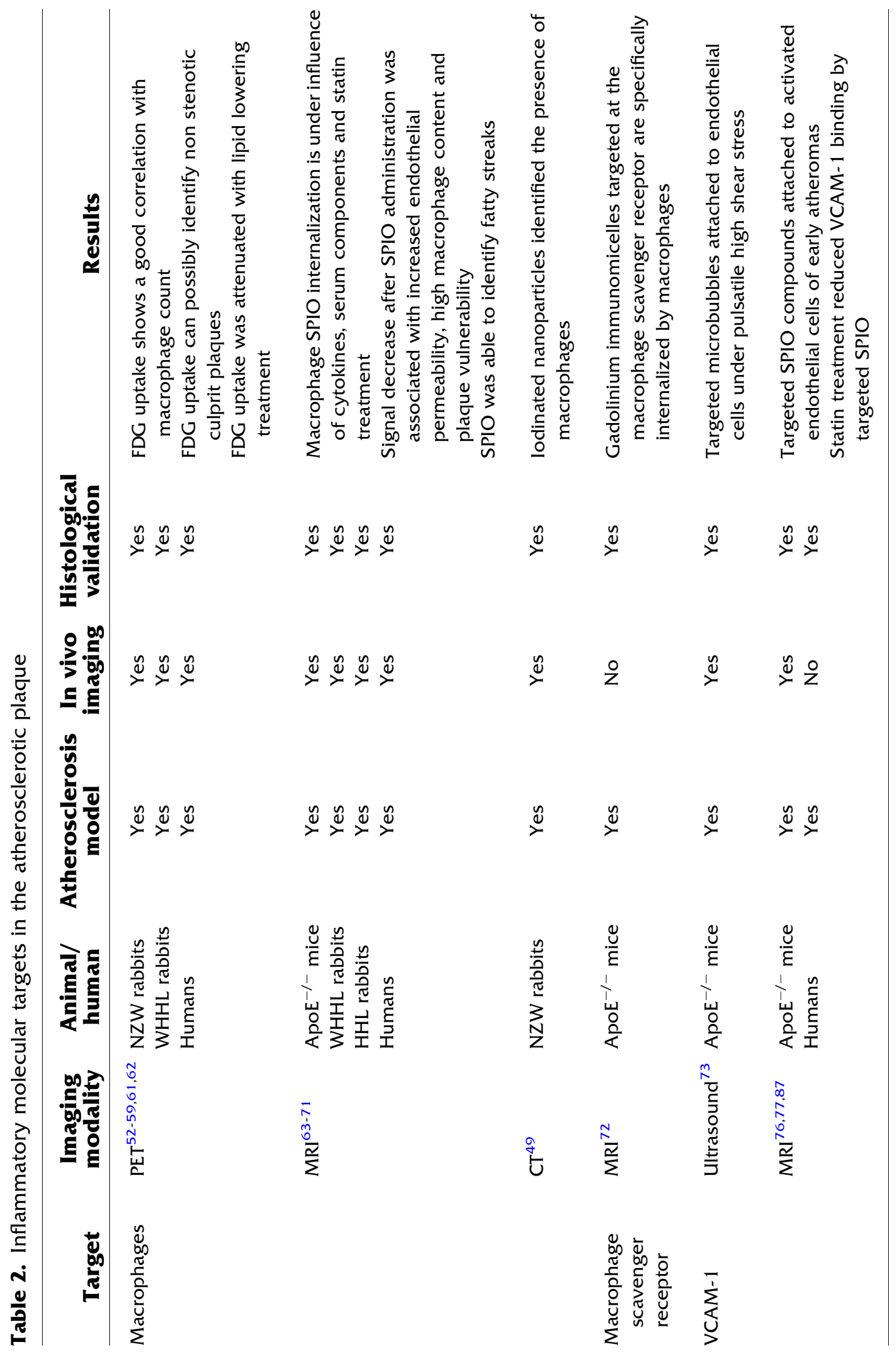




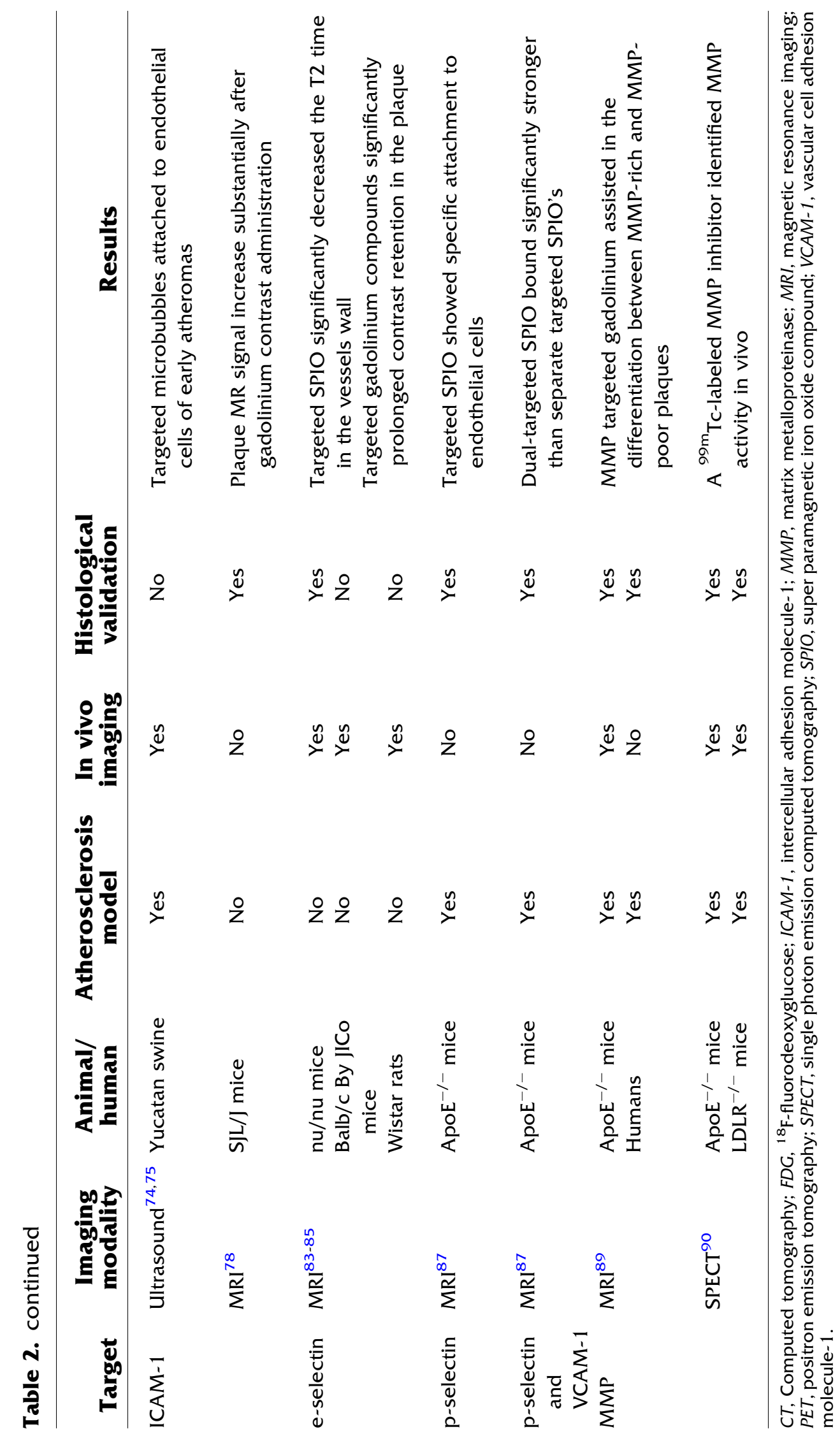




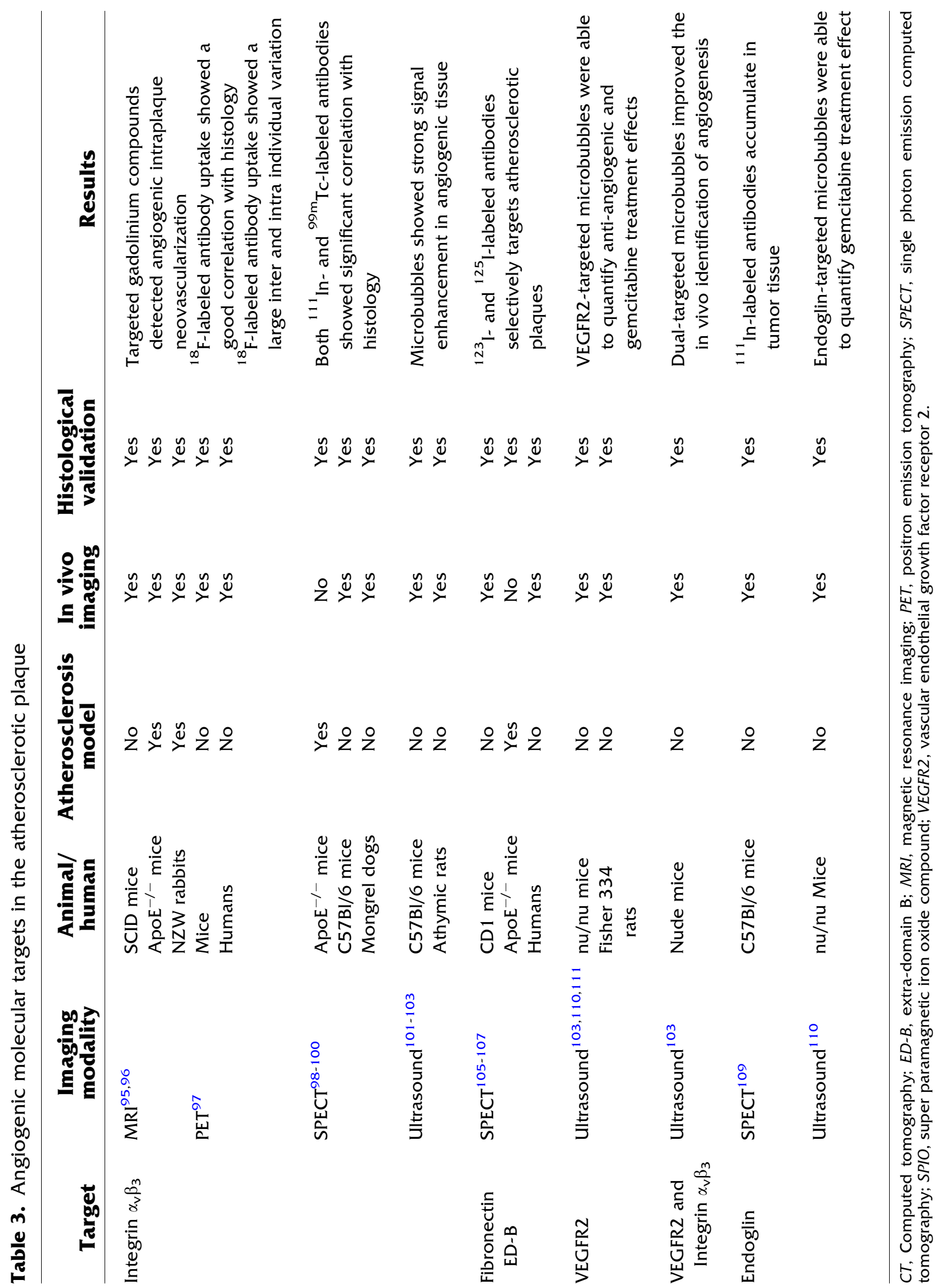


analogue taken up by all cells in proportion to their metabolic activity, especially glycolysis and is thus able to identify locations with high metabolism or disproportionate glucose use. The in vivo visualization and quantification of plaque inflammation by FDG-PET have been shown both in animals ${ }^{52-55}$ and humans. ${ }^{56-60}$

Davies et al investigated 12 patients who had all suffered a recent transient ischemic attack. Of the 12 stenotic lesions identified as the culprit lesion on conventional angiography, 7 showed a high FDG uptake. In the remaining three patients, three had a high FDG uptake in a nonstenotic lesion in the vascular territory compatible with the patients' symptoms. In these patients, the culprit lesion could not have been identified with angiography. FDG-PET had the potential to identify inflamed nonstenotic atherosclerotic lesions; however, no histology was obtained to confirm the findings. ${ }^{61}$

FDG-PET has also been used to evaluate treatment effects. Tahara et al randomized 43 patients undergoing FDG-PET for cancer screening to either statin treatment or dietary management only. After 3 months of treatment, FDG uptake in the atherosclerotic plaque had significantly decreased in the statin group, while no change was observed in the diet group. ${ }^{62}$ This intriguing
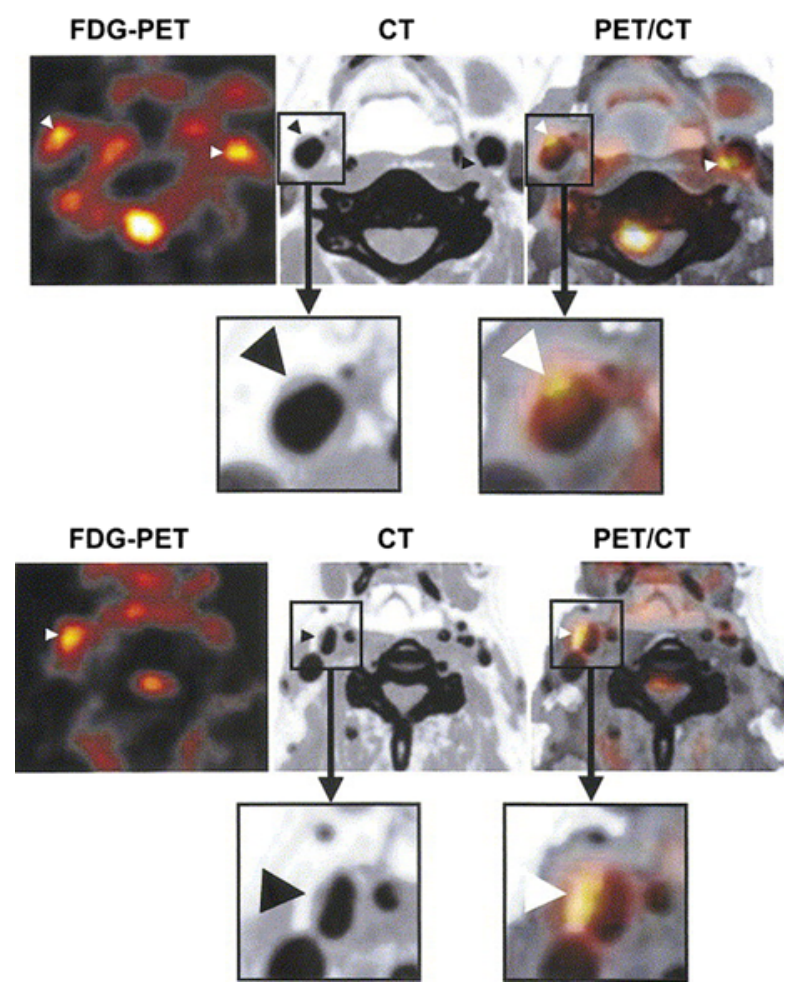

Figure 2. Transaxial images of FDG-PET (left), CT (middle), and co-registration of PET and CT (right) showing FDG uptakes in the carotid arterial plaques (arrowheads) of two patients. Reproduced with permission from Elsevier. ${ }^{62}$ observation suggests that FDG-PET has the potential to evaluate the effect of treatment on plaque inflammation.

Other contrast agents have been developed to identify macrophages in an atherosclerotic plaque. Rogers et al showed that in vitro SPIO compounds are nonspecifically taken up by macrophages under influence of cytokines, serum components and statin treatment. ${ }^{63} \mathrm{~A}$ number of in vivo MRI studies have shown that SPIO compounds localize macrophages in animal $^{64-66}$ and human ${ }^{67-71}$ atherosclerotic plaques (Figure 3). Hyafil et al used iodinated nanoparticles and showed a nonspecific uptake in macrophages in vitro. Subsequently, an in vivo study in 12 rabbits with induced atherosclerotic plaques showed that macrophage rich tissue could be detected by CT (Figure 4). ${ }^{49}$

Lipinski et al investigated gadolinium micelles and immuno-micelles targeted at the macrophage scavenger receptor in an ex vivo MRI study. Gadolinium micelles were nonspecifically taken up by macrophages. Notably, the specific up take of the immuno-micelles was significantly higher. These promising results suggest that immuno-micelles can be used to improve the detection of macrophages but of course they need to be reproduced in vivo. ${ }^{72}$

\section{Cellular Adhesion Molecules}

Endothelial expression of adhesion molecules has been identified as one of the earliest changes in the formation of atherosclerotic plaques. ${ }^{15}$ Vascular cell adhesion molecule-1 (VCAM-1) and intercellular adhesion molecule-1 (ICAM-1) are involved in the adhesion and subsequent extravasation of inflammatory cells. Both VCAM-1 and ICAM-1 are expressed by the endothelium overlying the atherosclerotic plaque. However, the most dominant expression of VCAM-1 and ICAM-1 is found at the adventitial site of the plaque and correlates with sites of vasa vasorum neovascularization, vascular permeability and high inflammatory cell density. ${ }^{18,30}$ VCAM-1 and ICAM-1 targeted contrast agents have been developed for ultrasound and MRI.

Kaufmann et al showed that VCAM-1-targeted microbubbles attach to activated murine endothelial cells in vitro, even under pulsatile high shear stress conditions. ${ }^{73}$ Subsequent in vivo experiments showed ultrasound signal enhancement in the aortic plaques of apoE deficient mice within 10 min after contrast injection. VCAM-1 expression was confirmed with histology. ${ }^{73}$ In a similar way, ICAM-1-targeted microbubbles were shown to specifically bind to endothelial cells expressing ICAM-1 in vitro. ${ }^{74}$ Demos et al investigated the attachment of ICAM-1-targeted microbubbles to atherosclerotic lesions induced in the femoral and carotid arteries of Yucatan miniswines. ${ }^{75}$ They 

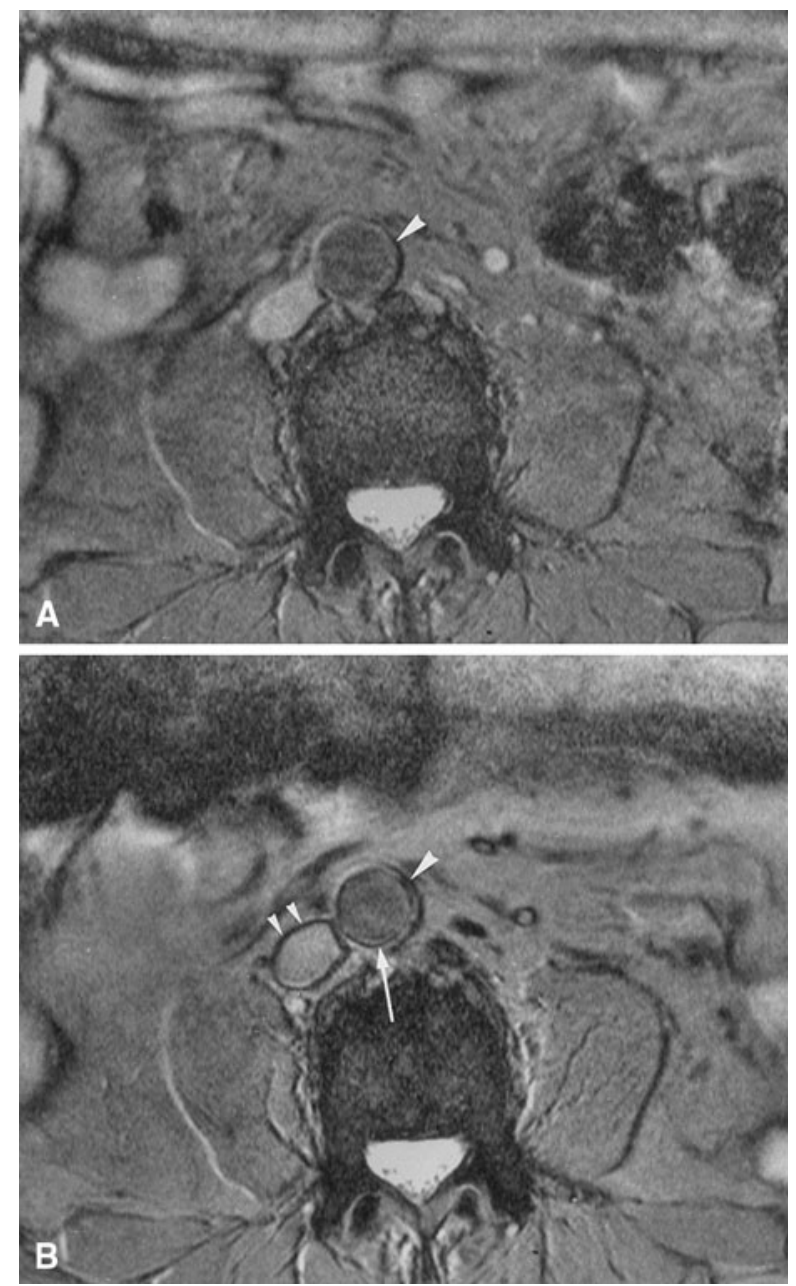

Figure 3. Axial 2D gradient-echo MRI of a patient. Pre- (A) and postcontrast $(\mathbf{B})$ images display the level of the aorta. On the precontrast image, the aortic wall is homogeneously hyperintense (A, arrowhead). Following SPIO administration, a pronounced signal loss of an area extending from the inner to the outer surface of the aortic wall can be seen ( $\mathbf{B}$, arrowhead $)$. This vessel segment was considered positive. Note, however, that there is also a low-intensity ring at the interface between the aortic wall and lumen on the postcontrast image $(\mathbf{B}$, long arrow). It is not possible to precisely determine whether the ring is truly confined to the aortic wall or to the lumen. This appearance is defined as a ring phenomenon, which is also seen in other vessels, such as the inferior vena cava (B, small arrowheads). Reproduced with permission from John Wiley \& Sons. ${ }^{67}$

found that ICAM-1-targeted microbubbles attached to the early stages of atherosclerotic plaque development (Figure 5), thus possibly identifying early stages of atherosclerotic vascular disease. ${ }^{75}$

VCAM-1-targeted gadolinium and SPIO compounds have been investigated in atherosclerotic apoE knockout mice and successfully identified VCAM-1 expressing endothelial cells in vivo. ${ }^{76,77}$ In addition, mice treated with statin therapy showed reduced contrast

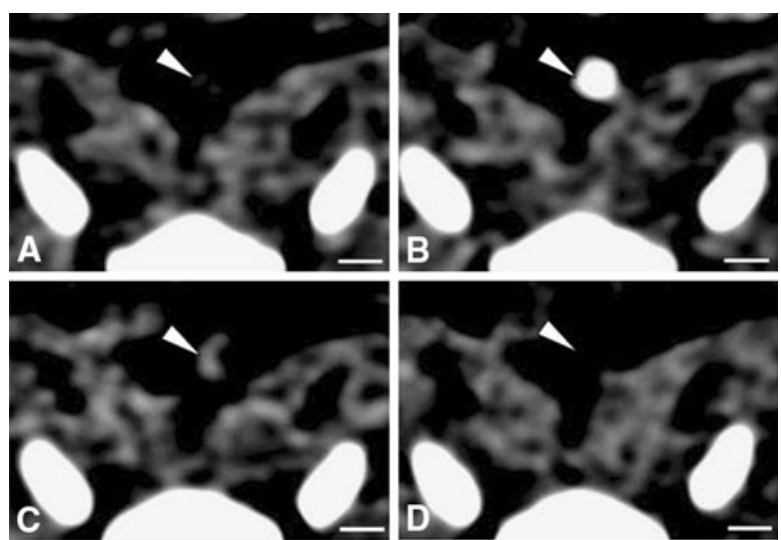

Figure 4. Axial views of the same atherosclerotic plaque (white arrowheads) in the aorta of a rabbit, obtained by CT before (A), during (B) and $2 \mathrm{~h}$ after the injection of an iodine nanoparticle contrast agent $(\mathbf{C})$ or a conventional iodine contrast agent (D). Adapted with permission from Macmillan Publishers Ltd. ${ }^{49}$

effect on MRI and reduced expression of VCAM-1 on histology. ${ }^{77}$ Ex vivo human carotid specimens confirmed that the VCAM-1-targeted contrast agents co-localized with VCAM-1 expressing endothelial cells, showing the feasibility of VCAM-1 imaging. ${ }^{77}$ ICAM-1targeted gadolinium liposomes have been investigated in mice with autoimmune encephalitis, but not yet in an atherosclerotic animal model. ${ }^{78}$

\section{Selectins}

Selectins are a group of pro-inflammatory endothelial cell adhesion molecules. E-selectin is up-regulated in proliferating endothelial cells and has been identified in angiogenic endothelial cells in tumor tissue. ${ }^{79-81}$ P-selectin is expressed both due to inflammation and ischemia-reperfusion damage. $^{79,82}$

Kang et al developed an e-selectin targeted SPIO compound and showed in vitro binding to human endothelial cells and consequently a clear T2 signal decrease on MRI, demonstrating the feasibility of e-selectin targeted molecular imaging. ${ }^{83,84}$ In vivo e-selectin targeted MRI contrast agents have been used to identify inflammation in hepatic and muscle tissue of mice. ${ }^{85,86}$ However, e-selectin targeted contrast has not yet been used for in vivo imaging of atherosclerotic plaques.

McAteer et al showed that p-selectin targeted SPIO compounds bind to atherosclerotic endothelial cells in vitro. ${ }^{87}$ Additionally, McAteer et al demonstrated the added value of dual-targeted molecular imaging, using a SPIO compound targeted to both VCAM-1 and p-selectin in apoE knockout mice. Compared to separate VCAM-1 or p-selectin targeted compounds the 

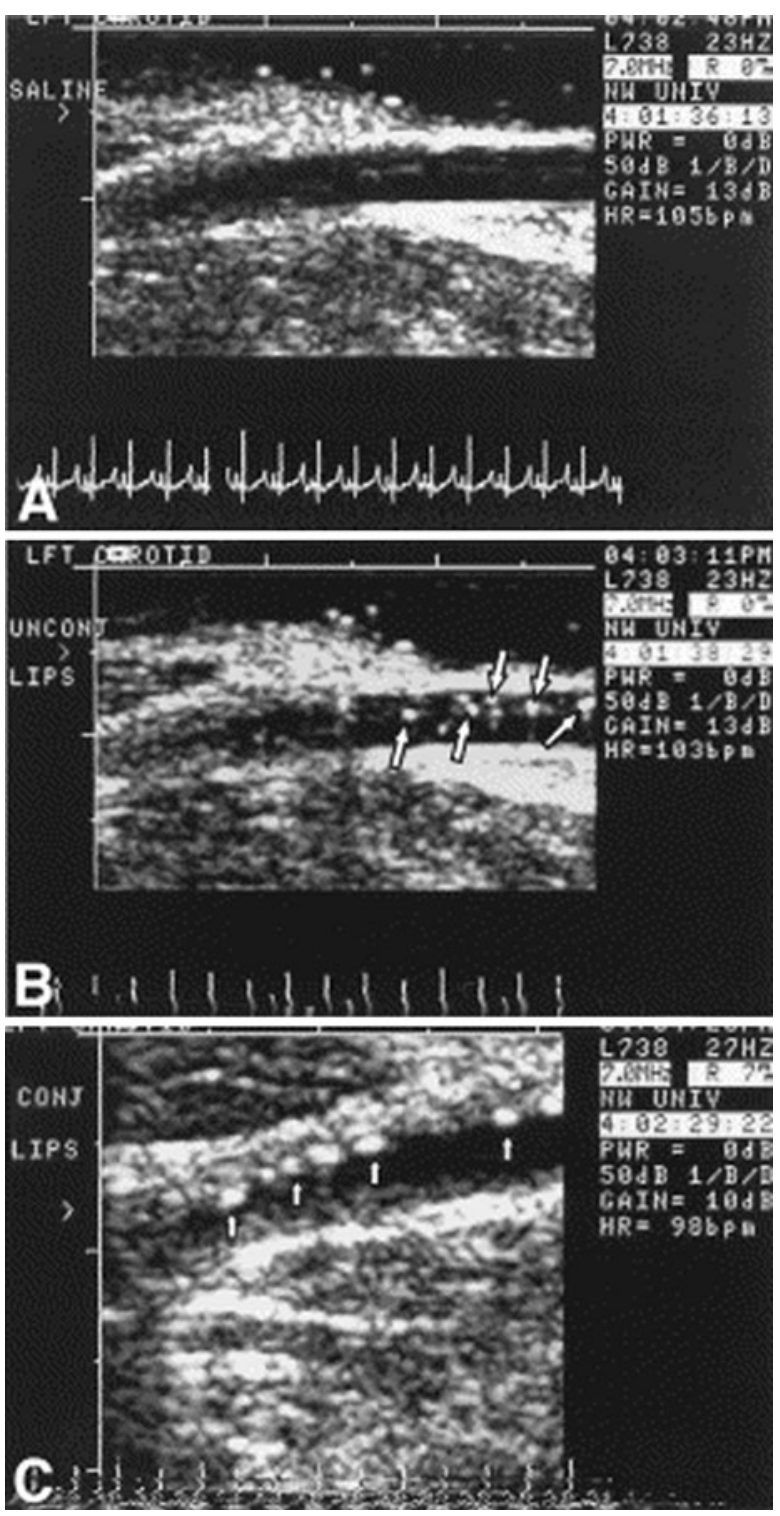

Figure 5. Transcutaneous ultrasound images of the atherosclerotic left carotid artery of a Yucatan miniswine. After injection of saline (A). After injection of nontargeted microbubbles (B) (arrows point to microbubbles within the lumen). After injection of ICAM-1 targeted microbubbles (C) (arrows point to microbubbles attached to the atherosclerotic plaque). Reproduced with permission from Elsevier. ${ }^{75}$

dual-targeted compound showed a significantly improved endothelial binding capacity on ex vivo MRI. $^{87}$

\section{Matrix Metalloproteinase}

Matrix metalloproteinases (MMP) are a group of extracellular matrix degrading enzymes predominantly excreted by macrophages. MMPs are associated with angiogenesis, the progression of atherosclerotic plaques and fibrous cap rupture. ${ }^{88}$ Lancelot et al showed that gadolinium immuno-micelles targeted at MMPs were capable of increasing the MRI signal both in vitro and in vivo. In addition, the ex vivo use of immuno-micelles facilitated discrimination between MMP-rich and MMPpoor plaques. ${ }^{89}$ Ohshima et al investigated the ability of SPECT in conjunction with a ${ }^{99 \mathrm{~m}} \mathrm{Tc}$-labeled broad spectrum MMP inhibitor to identify MMP activity in vivo. There was a significant correlation between the tracer uptake and the areas positively stained for macrophages, MMP-2 and MMP-9 on histology. ${ }^{90}$

\section{Summary}

The use of small molecule contrast agents, such as FDG and SPIO, allows for the evaluation of plaque inflammation due to their ability to pass the endothelial layer into the plaque and their subsequent uptake by macrophages. The visualization of cellular adhesion molecules and selectins may identify plaques actively recruiting monocytes. The co-localization of cellular adhesion molecules and selectins with vasa vasorum on histology might indicate an important additional role for adhesion molecules in the angiogenic process. Dualtargeted contrast agents may be used to identify low levels of expression of adhesion molecules and selectins, though this might also result in loss of specificity. The identification of MMP activity could be a technique to identify atherosclerotic plaques with activated macrophages and active remodeling of the extracellular matrix.

\section{ANGIOGENESIS-ASSOCIATED MOLECULAR TARGETS}

\section{Integrin $\alpha_{v} \beta_{3}$}

Integrins are a large family of cell surface receptors expressed by several cell types. Integrins play a role in cell adhesion, migration, and differentiation and are present both in normal and the atherosclerotic vessel walls. Integrin $\alpha_{\mathrm{v}} \beta_{3}$ is involved in the migration of endothelial cells across the basement membrane during angiogenesis. The expression of integrin $\alpha_{v} \beta_{3}$ has been shown to be a marker for angiogenic activity in the adventitial and intraplaque vasa vasorum. ${ }^{91-94}$

Integrin $\alpha_{v} \beta_{3}$-targeted gadolinium contrast has been investigated in a number of atherosclerotic animal models. In vivo MRI using an integrin $\alpha_{\mathrm{v}} \beta_{3}$-targeted gadolinium contrast agent showed a significant increase in the MRI signal in the atherosclerotic vessel wall. Expression of integrin $\alpha_{v} \beta_{3}$, proliferation of angiogenic vessels and neointima formation was confirmed by histology. ${ }^{95,96}$ Integrin-targeted contrast agents have also 
been developed for PET, ${ }^{97}$ SPECT, ${ }^{98-100}$ and ultrasound. ${ }^{101-103}$ These contrast agents have not yet been investigated in an animal model of atherosclerosis.

\section{Fibronectin Extra-Domain B}

The fibronectin molecule exists in a number of polymorphic forms resulting from alternative splicing. The extra-domain B (ED-B) isoform of fibronectin is not present in normal adult tissue, but is part of a temporary extracellular matrix formed during tissue remodeling. The ED-B fibronectin accumulates around the neovasculature during angiogenesis and does not accumulate around mature vessels, making the ED-B fibronectin a marker for angiogenesis. ${ }^{104}$ Immunohistochemical analysis demonstrated an increased expression of fibronectin around the vasa vasorum in both mice and human plaques. ${ }^{105}$

ED-B fibronectin-targeted monoclonal antibodies labeled with radionuclides have been developed to identify angiogenesis. Matter et al showed that ${ }^{125} \mathrm{I}-$ labeled monoclonal antibodies against ED-B fibronectin can be used to specifically target atherosclerotic plaques in apoE knockout mice and could be identified by ex vivo autoradiography. ${ }^{105}$ Although these results are promising, no in vivo imaging studies have been performed in an animal model of atherosclerosis. Nonetheless, in vivo studies have been performed in tumor models showing the potential for ED-B fibronectin imaging of angiogenesis. ${ }^{106,107}$

\section{Vascular Endothelial Growth Factor and Endoglin}

Two promising targets for molecular imaging are the vascular endothelial growth factor (VEGF) receptors and the transforming growth factor- $\beta$ binging receptor endoglin. Both targets are up-regulated by HIF- $1 \alpha{ }^{108}$ VEGF is the strongest known stimulant of angiogenesis and is responsible for vascular permeability, while endoglin is a cell membrane glycoprotein involved in vascular development and remodeling. VEGF-receptor2 and endoglin-targeted microbubbles and radionuclides have been used to study tumor angiogenesis in mice. ${ }^{103,109-111}$ Willmann et al investigated the in vivo binding of dual-targeted microbubbles targeted at the VEGF-receptor2 and integrin $\alpha_{\mathrm{v}} \beta_{3}$ to angiogenic tumor vessels in mice. Compared to single-targeted microbubbles, the dual-targeted microbubbles showed a significantly enhanced binding on ultrasound. ${ }^{103}$

\section{Summary}

Molecular imaging of active angiogenesis is a promising technique for the evaluation of intraplaque vasa vasorum sprouting from the adventitial vasa vasorum network. Integrin $\alpha_{\mathrm{v}} \beta_{3}$ and ED-B fibronectin are potential targets for the identification of intraplaque vasa vasorum due to their predominant localization around angiogenic vasculature. It has been shown that integrin $\alpha_{\mathrm{v}} \beta_{3}$ and ED-B imaging can be performed in vivo animals. These results have to be reproduced in humans. The VEGF receptors and endoglin are important receptors in the angiogenesis pathway. VEGF and endoglin-targeted imaging may theoretically be useful for identifying atherosclerotic plaques with active angiogenesis. Currently, the number of studies on VEGF and endoglin is limited and the development of a molecular imaging approach using these targets clearly needs further investigation.

\section{DRUG DELIVERY}

The nanotechnology used in molecular imaging opens possibilities for site-specific drug delivery. ${ }^{112,113}$ The localized delivery of drugs has clear advantages using lower dosages of more potent drugs and reaching high concentrations at the target location. The adverse effects of drugs may be reduced due to decreased concentration at nontarget sites. Nanoparticles have been developed that increase the concentration at the target location, some of which are already used in clinical practice. ${ }^{113}$ However, to date the targeted delivery of drugs to the atherosclerotic plaque has not yet been demonstrated.

Contrast ultrasound is perhaps the most promising modality for site-specific drug delivery. Microbubbles are able to carry drugs and genes that cannot otherwise be administrated (lipophilic drugs, proteins, silencing RNAs, DNA, etc.). ${ }^{114}$ The application of a high acoustic pressure (within the limits of standard ultrasound equipment) can be used to destroy the microbubbles and release the drugs at the desired location. ${ }^{115}$ Microbubbles have been used effectively as an in vivo drug and gene delivery system in studies of small animal models. ${ }^{114,116,117}$ However, studies in large animals and humans are lacking.

Besides the transportation of drugs, microbubbles have been shown to increase the local uptake of drugs. The exact mechanism that leads to this increased drug uptake is unknown, but several mechanisms have been investigated. The main mechanisms proposed are sonoporation and the induction of endocytosis. Sonoporation is the creation of transient micropores in the cellular membrane due to the oscillation and implosion of microbubbles in an ultrasound beam, thus increasing cellular membrane permeability. ${ }^{118}$ Increased uptake by ultrasound contrast-medicated sonoporation and endocytosis has been demonstrated in vitro. ${ }^{119-121}$ 


\section{CLINICAL APPLICATION}

Inflammation and angiogenesis play a central role in the pathophysiology of atherosclerosis. ${ }^{10,11,15,16,25,26}$ Moreover, atherosclerotic plaques with extensive inflammation and/or intraplaque vasa vasorum are probably at an increased risk of plaque rupture. ${ }^{4}$ Early detection of a vulnerable atherosclerotic plaque may help to identify patients at an increased risk for myocardial infarction or stroke, who may benefit from early pharmacological intervention. Molecular imaging of inflammation and angiogenesis can be used to identify early atherosclerotic lesions in animals before anatomical wall abnormalities are visible, thus possibly allowing for early preventive interventions. ${ }^{66,77}$ In more advanced atherosclerotic disease, molecular imaging may distinguish between culprit and nonculprit lesions, potentially identifying patients at increased risk of developing symptomatic disease. ${ }^{56,61,68}$

Due to the tortuous and ever moving nature of the coronary arteries, imaging of coronary atherosclerotic plaques is a major challenge. The use of catheter-based intravascular imaging techniques has been shown to accurately visualize coronary atherosclerotic plaques. Intravascular ultrasound and optical coherence tomography are currently available in clinical practice and novel catheter-based imaging techniques such as intravascular MRI, thermography, and spectroscopy are in various stages of development. ${ }^{37}$ Noninvasive evaluation of coronary atherosclerotic plaques is more challenging. $\mathrm{CT}$ is frequently used to evaluate the coronary anatomy, but noninvasive molecular evaluation of the coronary arteries using CT has not yet been investigated. Because atherosclerosis is a systemic inflammatory disease and local changes in macrophage content and vasa vasorum density are often uniformly present in different vascular beds, ${ }^{34}$ the presence and composition of atherosclerotic plaques in the peripheral arteries can be used as an indication for atherosclerotic disease of the coronary arteries. This concept was investigated in a recent prospective follow-up study by Hellings et al, ${ }^{122}$ who showed that local histological composition of atherosclerotic plaques in the carotid arteries was an independent predictor of future cardiovascular events. The predictive value of molecular imaging of atherosclerotic plaques in the peripheral arteries as a marker for coronary artery disease has not yet been determined.

Current technical limitations of the individual imaging techniques might be overcome by multimodality imaging. Multimodality imaging combines different imaging modalities, using the advantages of each individual technique to improve the overall accuracy. For example, in current clinical practice PET is almost always used with co-registration of CT. This allows for the combination of the highly accurate and quantifiable assessment of biological activity by PET and the high resolution anatomical information provided by CT (Figure 2). ${ }^{61,123,124}$

The identification of suitable target-ligand combinations is a complex process. Molecular imaging requires the identification of a disease-specific target with high expression and a targeting ligand with favorable binding kinetics to the target: the contrast agent should bind to the target in quantities great enough to overwhelm the signal from nonspecifically retained contrast. Additionally, the imaging system should have sufficient sensitivity to detect the targeted agents present at the site of pathology. ${ }^{125}$ Most of the contrast agents and targets discussed in the present review have already shown their value in vivo in animal models of atherosclerosis. However, the translation of molecular imaging techniques to the human setting is still limited, making their application and accuracy in humans uncertain. Before the introduction of these molecular imaging techniques into the clinical setting, the safety of the diagnostic contrast agents has to be confirmed, adhering to the same stringent safety criteria as used for therapeutic drugs. The current experience with the pharmacokinetics and toxicity of the contrast agents is limited and mainly based on nontargeted contrast agents. The effect of the ligands bound to the different contrast agents must be studied before studies can be performed in patients. Most of the studies did not evaluate the effects of variable dosing, repeated measurements, and routes of disposal.

The use of molecular imaging has led to substantial advances in oncologic drug development. In different stages of drug development, from target validation to phase 3 trials, molecular imaging-derived measurements have been used as a surrogate endpoint and thus have facilitated drug development and implementation. ${ }^{126}$ The availability of accurate surrogate endpoints will benefit the development of new cardiovascular drugs as well. ${ }^{3}$ Molecular imaging may provide more insight into the pathophysiological mechanisms of atherosclerosis, aiding in target identification and validation in vivo. Furthermore, the use of molecular imaging may reduce the follow-up time needed in clinical trials, improve drug substance selection, and monitor treatment effects during pharmacological trials. A number of studies have shown that the evaluation of anti-inflammatory treatment effects of lipid lowering treatment by molecular imaging of atherosclerosis is feasible. ${ }^{55,62,77}$

\section{CONCLUSION}

Molecular imaging of intraplaque vasa vasorum is feasible and effective in ex vivo experiments and in vivo 
animal models by the detection of inflammation and angiogenesis. The introduction of molecular imaging techniques in clinical practice will increase the understanding of the role of inflammation and angiogenesis by elucidating their temporal relation in the disease process. The ability of molecular imaging to detect subclinical atherosclerotic disease and to identify vulnerable plaques may cause a revolution in the management of patients with atherosclerosis.

\section{Acknowledgements}

Dr. Feinstein has received speaker's honorarium/ consulting fees from Takeda, Merck, Abbott, and GE Health Care, and research funding from Takeda. The other authors have no relationships with industry to be reported.

\section{Open Access}

This article is distributed under the terms of the Creative Commons Attribution Noncommercial License which permits any noncommercial use, distribution, and reproduction in any medium, provided the original author(s) and source are credited.

\section{References}

1. Weissleder R, Pittet MJ. Imaging in the era of molecular oncology. Nature 2008;452:580-9.

2. Sanz J, Fayad ZA. Imaging of atherosclerotic cardiovascular disease. Nature 2008;451:953-7.

3. Kastelein JJP, de Groot E. Ultrasound imaging techniques for the evaluation of cardiovascular therapies. Eur Heart J 2008;29: 849-58.

4. Naghavi M, Libby P, Falk E, Casscells SW, Litovsky S, Rumberger J, et al. From vulnerable plaque to vulnerable patient: A call for new definitions and risk assessment strategies: Part I. Circulation 2003;108:1664-72.

5. Barger AC, Beeuwkes R, Lainey LL, Silverman KJ. Hypothesis: Vasa vasorum and neovascularization of human coronary arteries. A possible role in the pathophysiology of atherosclerosis. N Engl J Med 1984;310:175-7.

6. Moreno PR, Purushothaman KR, Zias E, Sanz J, Fuster V. Neovascularization in human atherosclerosis. Curr Mol Med 2006;6:457-77.

7. Langheinrich AC, Kampschulte M, Buch T, Bohle RM. Vasa vasorum and atherosclerosis-Quid novi? Thromb Haemost 2007;97:873-9.

8. O'Brien ER, Garvin MR, Dev R, Stewart DK, Hinohara T, Simpson JB, et al. Angiogenesis in human coronary atherosclerotic plaques. Am J Pathol 1994;145:883-94.

9. Jeziorska M, Woolley DE. Neovascularization in early atherosclerotic lesions of human carotid arteries: Its potential contribution to plaque development. Hum Pathol 1999;30:919-25.

10. Moulton KS. Angiogenesis in atherosclerosis: Gathering evidence beyond speculation. Curr Opin Lipidol 2006;17:548-55.

11. Gössl M, Versari D, Lerman LO, Chade AR, Beighley PE, Erbel $\mathrm{R}$, et al. Low vasa vasorum densities correlate with inflammation and subintimal thickening: Potential role in location-Determination of atherogenesis. Atherosclerosis 2009;206:362-8.
12. Mulligan-Kehoe MJ. The vasa vasorum in diseased and nondiseased arteries. Am J Physiol Heart Circ Physiol 2010;298:H295305.

13. Purushothaman KR, Fuster V, O'Connor WN, Moreno PR. Neovascularization is the most powerful independent predictor for progression to disruption in high-risk atherosclerotic plaques (abstract). J Am Coll Cardiol 2003;41:352-3.

14. Moreno PR, Purushothaman KR, Fuster V, Echeverri D, Truszczynska H, Sharma SK, et al. Plaque neovascularization is increased in ruptured atherosclerotic lesions of human aorta: Implications for plaque vulnerability. Circulation 2004;110: 2032-8.

15. Ross R. Atherosclerosis-An inflammatory disease. N Engl J Med 1999;340:115-26.

16. Fuster V, Moreno PR, Fayad ZA, Corti R, Badimon JJ. Atherothrombosis and high-risk plaque: Part I: Evolving concepts. J Am Coll Cardiol 2005;46:937-54.

17. Moulton KS, Vakili K, Zurakowski D, Soliman M, Butterfield C, Sylvin E, et al. Inhibition of plaque neovascularization reduces macrophage accumulation and progression of advanced atherosclerosis. Proc Natl Acad Sci USA 2003;100:4736-41.

18. O'Brien KD, Allen MD, McDonald TO, Chait A, Harlan JM, Fishbein D, et al. Vascular cell adhesion molecule-1 is expressed in human coronary atherosclerotic plaques. Implications for the mode of progression of advanced coronary atherosclerosis. J Clin Invest 1993;92:945-51.

19. Ribatti D, Levi-Schaffer F, Kovanen PT. Inflammatory angiogenesis in atherogenesis-A double-edged sword. Ann Med 2008;40:606-21.

20. Ritman EL, Lerman A. The dynamic vasa vasorum. Cardiovasc Res 2007;75:649-58.

21. Heistad DD, Marcus ML, Larsen GE, Armstrong ML. Role of vasa vasorum in nourishment of the aortic wall. Am J Physiol Heart Circ Physiol 1981;240:H781-7.

22. Williams JK, Armstrong ML, Heistad DD. Blood flow through new microvessels: Factors that affect regrowth of vasa vasorum. Am J Physiol Heart Circ Physiol 1988;254:H126-32.

23. Stefanadis C, Vlachopoulos C, Karayannacos P, Boudoulas H, Stratos C, Filippides T, et al. Aorta: Structure/function: Effect of vasa vasorum flow on structure and function of the aorta in experimental animals. Circulation 1995;91:2669-78.

24. Groszek E, Grundy S. The possible role of the arterioal microcirculation in the pathogenisis of atherosclerosis (Editorial). J Chronic Dis 1980;33:679-84.

25. Sluimer JC, Daemen MJ. Novel concepts in atherogenesis: Angiogenesis and hypoxia in atherosclerosis. $\mathrm{J}$ Pathol 2009;218:7-29.

26. Gössl M, Versari D, Hildebrandt H, Bajanowski T, Sangiorgi G, Erbel R, et al. Segmental heterogeneity of vasa vasorum neovascularization in human coronary atherosclerosis. JACC Cardiovasc Imaging 2010;3:32-40.

27. Bjornheden T, Levin M, Evaldsson M, Wiklund O. Evidence of hypoxic areas within the arterial wall in vivo. Arterioscler Thromb Vasc Biol 1999;19:870-6.

28. Mayr M, Sidibe A, Zampetaki A. The paradox of hypoxic and oxidative stress in atherosclerosis (Editorial). J Am Coll Cardiol 2008;51:1266-7.

29. Sluimer JC, Gasc JM, van Wanroij JL, Kisters N, Groeneweg M, Sollewijn Gelpke MD, et al. Hypoxia, hypoxia-inducible transcription factor, and macrophages in human atherosclerotic plaques are correlated with intraplaque angiogenesis. J Am Coll Cardiol 2008;51:1258-65.

30. O'Brien KD, McDonald TO, Chait A, Allen MD, Alpers CE. Neovascular expression of e-selectin, intercellular adhesion 
molecule-1, and vascular cell adhesion molecule-1 in human atherosclerosis and their relation to intimal leukocyte content. Circulation 1996;93:672-82.

31. Dunmore BJ, McCarthy MJ, Naylor AR, Brindle NPJ. Carotid plaque instability and ischemic symptoms are linked to immaturity of microvessels within plaques. J Vasc Surg 2007;45:155-9.

32. Sluimer J, Kolodgie F, Bijnens AP, Maxfield K, Pacheco E, Kutys B, et al. Thin-walled microvessels in human coronary atherosclerotic plaques show incomplete endothelial junctions relevance of compromised structural integrity for intraplaque microvascular leakage. J Am Coll Cardiol 2009;53:1517-27.

33. Biedermann BC, Coll B, Adam D, Feinstein SB. Arterial microvessels: An early or late sign of atherosclerosis? (Letter). J Am Coll Cardiol 2008;52:968-9.

34. Fleiner M, Kummer M, Mirlacher M, Sauter G, Cathomas G, Krapf R, et al. Arterial neovascularization and inflammation in vulnerable patients: Early and late signs of symptomatic atherosclerosis. Circulation 2004;110:2843-50.

35. Kwon HM, Sangiorgi G, Ritman EL, McKenna C, Holmes DR, Schwartz RS, et al. Enhanced coronary vasa vasorum neovascularization in experimental hypercholesterolemia. J Clin Invest 1998;101:1551-6.

36. Herrmann J, Lerman LO, Rodriguez-Porcel M, Holmes DR, Richardson DM, Ritman EL, et al. Coronary vasa vasorum neovascularization precedes epicardial endothelial dysfunction in experimental hypercholesterolemia. Cardiovasc Res 2001;51: $762-6$.

37. MacNeill BD, Lowe HC, Takano M, Fuster V, Jang IK. Intravascular modalities for detection of vulnerable plaque: Current status. Arterioscler Thromb Vasc Biol 2003;23:1333-42.

38. Davies JR, Rudd JH, Weissberg PL. Molecular and metabolic imaging of atherosclerosis. J Nucl Med 2004;45:1898-907.

39. Choudhury RP, Fisher EA. Molecular imaging in atherosclerosis, thrombosis, and vascular inflammation. Arterioscler Thromb Vasc Biol 2009;29:983-91.

40. Krause W. Delivery of diagnostic agents in computed tomography. Adv Drug Deliv Rev 1999;37:159-73.

41. Huang B, Law MWM, Khong PL. Whole-body PET/CT scanning: Estimation of radiation dose and cancer risk. Radiology 2009;251:166-74.

42. Weissleder R, Elizondo G, Wittenberg J, Rabito CA, Bengele $\mathrm{HH}$, Josephson L. Ultrasmall superparamagnetic iron oxide: Characterization of a new class of contrast agents for MR imaging. Radiology 1990;175:489-93.

43. Issa N, Poggio ED, Fatica RA, Patel R, Ruggieri PM, Heyka RJ. Nephrogenic systemic fibrosis and its association with gadolinium exposure during MRI. Cleve Clin J Med 2008;75:95-111.

44. Kuo PH, Kanal E, Abu-Alfa AK, Cowper SE. Gadolinium-based MR contrast agents and nephrogenic systemic fibrosis. Radiology 2007;242:647-9.

45. Feinstein SB. The powerful microbubble: From bench to bedside, from intravascular indicator to therapeutic delivery system, and beyond. Am J Physiol Heart Circ Physiol 2004;287:H450-7.

46. Schneider M. Molecular imaging and ultrasound-assisted drug delivery. J Endourol 2008;22:795-802.

47. Voigt JU. Ultrasound molecular imaging. Methods 2009;48:92-7.

48. Main M, Goldman J, Grayburn P. Ultrasound contrast agents: Balancing safety versus efficacy. Expert Opin Drug Saf 2009;8:49-56.

49. Hyafil F, Cornily JC, Feig JE, Gordon R, Vucic E, Amirbekian V, et al. Noninvasive detection of macrophages using a nanoparticulate contrast agent for computed tomography. Nat Med 2007; 13:636-41.
50. Pontone G, Andreini D, Bartorelli AL, Cortinovis S, Mushtaq S, Bertella E, et al. Diagnostic accuracy of coronary computed tomography angiography: A comparison between prospective and retrospective electrocardiogram triggering. J Am Coll Cardiol 2009;54:346-55.

51. Nash K, Hafeez A, Hou S. Hospital-acquired renal insufficiency. Am J Kidney Dis 2002;39:930-6.

52. Lederman RJ, Raylman RR, Fisher SJ, Kison PV, San H, Nabel EG, et al. Detection of atherosclerosis using a novel positronsensitive probe and 18-fluorodeoxyglucose (FDG). Nucl Med Commun 2001;22:747-53.

53. Ogawa M, Ishino S, Mukai T, Asano D, Teramoto N, Watabe H, et al. (18)F-FDG accumulation in atherosclerotic plaques: Immunohistochemical and PET imaging study. J Nucl Med 2004; 45:1245-50

54. Tawakol A, Migrino RQ, Hoffmann U, Abbara S, Houser S, Gewirtz $\mathrm{H}$, et al. Noninvasive in vivo measurement of vascular inflammation with F-18 fluorodeoxyglucose positron emission tomography. J Nucl Cardiol 2005;12:294-301.

55. Ogawa M, Magata Y, Kato T, Hatano K, Ishino S, Mukai T, et al. Application of 18F-FDG PET for monitoring the therapeutic effect of antiinflammatory drugs on stabilization of vulnerable atherosclerotic plaques. J Nucl Med 2006;47:1845-50.

56. Rudd JHF, Warburton EA, Fryer TD, Jones HA, Clark JC, Antoun $\mathrm{N}$, et al. Imaging atherosclerotic plaque inflammation with [18F]-fluorodeoxyglucose positron emission tomography. Circulation 2002;105:2708-11.

57. Tawakol A, Migrino RQ, Bashian GG, Bedri S, Vermylen D, Cury RC, et al. In vivo ${ }^{18} \mathrm{~F}$-fluorodeoxyglucose positron emission tomography imaging provides a noninvasive measure of carotid plaque inflammation in patients. J Am Coll Cardiol 2006;48: 1818-24.

58. Tahara N, Kai H, Yamagishi SI, Mizoguchi M, Nakaura H, Ishibashi M, et al. Vascular inflammation evaluated by [18F]fluorodeoxyglucose positron emission tomography is associated with the metabolic syndrome. J Am Coll Cardiol 2007;49: 1533-9.

59. Tahara N, Kai H, Nakaura H, Mizoguchi M, Ishibashi M, Kaida $\mathrm{H}$, et al. The prevalence of inflammation in carotid atherosclerosis: Analysis with fluorodeoxyglucose positron emission tomography. Eur Heart J 2007;28:2243-8.

60. Rudd JHF, Myers KS, Bansilal S, Machac J, Pinto CA, Tong C, et al. Atherosclerosis inflammation imaging with 18F-FDG PET: Carotid, iliac, and femoral uptake reproducibility, quantification methods, and recommendations. J Nucl Med 2008;49:871-8.

61. Davies JR, Rudd JHF, Fryer TD, Graves MJ, Clark JC, Kirkpatrick PJ, et al. Identification of culprit lesions after transient ischemic attack by combined $18 \mathrm{~F}$ fluorodeoxyglucose positronemission tomography and high-resolution magnetic resonance imaging. Stroke 2005;36:2642-7.

62. Tahara N, Kai H, Ishibashi M, Nakaura H, Kaida H, Baba K, et al. Simvastatin attenuates plaque inflammation: Evaluation by fluorodeoxyglucose positron emission tomography. J Am Coll Cardiol 2006;48:1825-31.

63. Rogers WJ, Basu P. Factors regulating macrophage endocytosis of nanoparticles: Implications for targeted magnetic resonance plaque imaging. Atherosclerosis 2005;178:67-73.

64. Schmitz SA, Coupland SE, Gust R, Winterhalter S, Wagner S, Kresse M, et al. Superparamagnetic iron oxide-enhanced MRI of atherosclerotic plaques in Watanabe hereditable hyperlipidemic rabbits. Invest Radiol 2000;35:460-71.

65. Ruehm SG, Corot C, Vogt P, Kolb S, Debatin JF. Magnetic resonance imaging of atherosclerotic plaque with ultrasmall 
superparamagnetic particles of iron oxide in hyperlipidemic rabbits. Circulation 2001;103:415-22.

66. Litovsky S, Madjid M, Zarrabi A, Casscells SW, Willerson JT, Naghavi M. Superparamagnetic iron oxide-based method for quantifying recruitment of monocytes to mouse atherosclerotic lesions in vivo: Enhancement by tissue necrosis factor-[alpha], interleukin-1[beta], and interferon-[gamma]. Circulation 2003;107:1545-9.

67. Schmitz SA, Taupitz M, Wagner S, Wolf KJ, Beyersdorff D, Hamm B. Magnetic resonance imaging of atherosclerotic plaques using superparamagnetic iron oxide particles. J Magn Reson Imaging 2001;14:355-61.

68. Kooi ME, Cappendijk VC, Cleutjens KBJM, Kessels AGH, Kitslaar PJEHM, Borgers M, et al. Accumulation of ultrasmall superparamagnetic particles of iron oxide in human atherosclerotic plaques can be detected by in vivo magnetic resonance imaging. Circulation 2003;107:2453-8.

69. Trivedi RA, U-King-Im JM, Graves MJ, Cross JJ, Horsley J, Goddard MJ, et al. In vivo detection of macrophages in human carotid atheroma: Temporal dependence of ultrasmall superparamagnetic particles of iron oxide-enhanced MRI. Stroke 2004;35:1631-5.

70. Trivedi RA, Mallawarachi C, U-King-Im JM, Graves MJ, Horsley J, Goddard MJ, et al. Identifying inflamed carotid plaques using in vivo USPIO-enhanced MR imaging to label plaque macrophages. Arterioscler Thromb Vasc Biol 2006;26:1601-6.

71. Kawahara I, Nakamoto M, Kitagawa N, Tsutsumi K, Nagata I, Morikawa $\mathrm{M}$, et al. Potential of magnetic resonance plaque imaging using superparamagnetic particles of iron oxide for the detection of carotid plaque. Neurol Med Chir (Tokyo) 2008;48:157-61.

72. Lipinski MJ, Amirbekian V, Frias JC, Aguinaldo JGS, Mani V, Briley-Saebo KC, et al. MRI to detect atherosclerosis with gadolinium-containing immunomicelles targeting the macrophage scavenger receptor. Magn Reson Med 2006;56:601-10.

73. Kaufmann BA, Sanders JM, Davis C, Xie A, Aldred P, Sarembock IJ, et al. Molecular imaging of inflammation in atherosclerosis with targeted ultrasound detection of vascular cell adhesion molecule-1. Circulation 2007;116:276-84.

74. Villanueva FS, Jankowski RJ, Klibanov S, Pina ML, Alber SM, Watkins SC, et al. Microbubbles targeted to intercellular adhesion molecule-1 bind to activated coronary artery endothelial cells. Circulation 1998;98:1-5.

75. Demos SM, Alkan-Onyuksel H, Kane BJ, Ramani K, Nagaraj A, Greene $\mathrm{R}$, et al. In vivo targeting of acoustically reflective liposomes for intravascular and transvascular ultrasonic enhancement. J Am Coll Cardiol 1999;33:867-75.

76. Kelly KA, Allport JR, Tsourkas A, Shinde-Patil VR, Josephson L, Weissleder R. Detection of vascular adhesion molecule-1 expression using a novel multimodal nanoparticle. Circ Res 2005;96:327-36.

77. Nahrendorf M, Jaffer FA, Kelly KA, Sosnovik DE, Aikawa E, Libby $\mathrm{P}$, et al. Noninvasive vascular cell adhesion molecule-1 imaging identifies inflammatory activation of cells in atherosclerosis. Circulation 2006;114:1504-11.

78. Sipkins DA, Gijbels K, Tropper FD, Bednarski M, Li KCP, Steinman L. ICAM-1 expression in autoimmune encephalitis visualized using magnetic resonance imaging. J Neuroimmunol 2000;104:1-9.

79. Bevilacqua MP, Nelson RM. Selectins. J Clin Invest 1993;91:379-87.

80. Kräling BM, Razon MJ, Boon LM, Zurakowski D, Seachord C, Darveau RP, et al. E-selectin is present in proliferating endothelial cells in human hemangiomas. Am $\mathrm{J}$ Pathol 1996;148:1181-91.

81. Bischoff J, Brasel C, Krling B, Vranovska K. E-selectin is upregulated in proliferating endothelial cells in vitro. Microcirculation 1997;4:279-87.

82. Kanwar S, Smith CW, Kubes P. An absolute requirement for p-selectin in ischemia/reperfusion-induced leukocyte recruitment in cremaster muscle. Microcirculation 1998;5:281-7.

83. Kang HW, Josephson L, Petrovsky A, Weissleder R, Bogdanov A. Magnetic resonance imaging of inducible e-selectin expression in human endothelial cell culture. Bioconjug Chem 2002;13:122-7.

84. Kang HW, Torres D, Wald L, Weissleder R, Bogdanov AA. Targeted imaging of human endothelial-specific marker in a model of adoptive cell transfer. Lab Invest 2006;86:599-609.

85. Boutry S, Burtea C, Laurent S, Toubeau G, Vander Elst L, Muller RN. Magnetic resonance imaging of inflammation with a specific selectin-targeted contrast agent. Magn Reson Med 2005;53:800-7.

86. Radermacher KA, Beghein N, Boutry S, Laurent S, Elst LV, Muller RN, et al. In vivo detection of inflammation using pegylated iron oxide particles targeted at e-selectin: A multimodal approach using MR imaging and EPR spectroscopy. Invest Radiol 2009;44:398-404.

87. McAteer MA, Schneider JE, Ali ZA, Warrick N, Bursill CA, von zur Muhlen C, et al. Magnetic resonance imaging of endothelial adhesion molecules in mouse atherosclerosis using dual-targeted microparticles of iron oxide. Arterioscler Thromb Vasc Biol 2008;28:77-83.

88. Galis ZS, Khatri JJ. Matrix metalloproteinases in vascular remodeling and atherogenesis: The good, the bad, and the ugly. Circ Res 2002;90:251-62.

89. Lancelot E, Amirbekian V, Brigger I, Raynaud JS, Ballet S, David C, et al. Evaluation of matrix metalloproteinases in atherosclerosis using a novel noninvasive imaging approach. Arterioscler Thromb Vasc Biol 2008;28:425-32.

90. Ohshima S, Petrov A, Fujimoto S, Zhou J, Azure M, Edwards DS, et al. Molecular imaging of matrix metalloproteinase expression in atherosclerotic plaques of mice deficient in apolipoprotein E or low-density-lipoprotein receptor. J Nucl Med 2009;50:612-7.

91. Hynes RO. Integrins: A family of cell surface receptors. Cell 1987;48:549-54

92. Hoshiga M, Alpers CE, Smith LL, Giachelli CM, Schwartz SM. \{alpha\}vB3 Integrin expression in normal and atherosclerotic artery. Circ Res 1995;77:1129-35.

93. Brooks PC, Clark RA, Cheresh DA. Requirement of vascular integrin alpha $\mathrm{v}$ beta 3 for angiogenesis. Science 1994;264: 569-71.

94. Haubner R. Alphavbeta3-integrin imaging: A new approach to characterise angiogenesis? Eur J Nucl Med Mol Imaging 2006;33 Suppl 1:54-63.

95. Winter PM, Morawski AM, Caruthers SD, Fuhrhop RW, Zhang $\mathrm{H}$, Williams TA, et al. Molecular imaging of angiogenesis in early-stage atherosclerosis with alpha(v)beta3-integrin-targeted nanoparticles. Circulation 2003;108:2270-4.

96. Burtea C, Laurent S, Murariu O, Rattat D, Toubeau G, Verbruggen $\mathrm{A}$, et al. Molecular imaging of alpha $\mathrm{v}$ beta 3 integrin expression in atherosclerotic plaques with a mimetic of RGD peptide grafted to Gd-DTPA. Cardiovasc Res 2008;78:148-57.

97. Haubner R, Weber W, Beer A, Vabuliene E, Reim D, Sarbia M, et al. Noninvasive visualization of the activated alphavbeta3 integrin in cancer patients by positron emission tomography and [18F]Galacto-RGD. PLoS Med 2005;2:e70. 
98. Meoli D, Sadeghi M, Krassilnikova S, Bourke B, Giordano F, Dione D, et al. Noninvasive imaging of myocardial angiogenesis following experimental myocardial infarction. J Clin Invest 2004;113:1684-91.

99. Sadeghi MM, Krassilnikova S, Zhang J, Gharaei AA, Fassaei HR, Esmailzadeh L, et al. Detection of injury-induced vascular remodeling by targeting activated \{alpha\} $v\{$ beta 3 integrin in vivo. Circulation 2004;110:84-90.

100. Hua J, Dobrucki LW, Sadeghi MM, Zhang J, Bourke BN, Cavaliere $\mathrm{P}$, et al. Noninvasive imaging of angiogenesis with a 99mTc-labeled peptide targeted at [alpha]v[beta]3 integrin after murine hindlimb ischemia. Circulation 2005;111:3255-60.

101. Ellegala DB, Leong-Poi H, Carpenter JE, Klibanov AL, Kaul S, Shaffrey ME, et al. Imaging tumor angiogenesis with contrast ultrasound and microbubbles targeted to [alpha]v[beta]3. Circulation 2003;108:336-41.

102. Leong-Poi H, Christiansen J, Klibanov AL, Kaul S, Lindner JR. Noninvasive assessment of angiogenesis by ultrasound and microbubbles targeted to alpha(v)-integrins. Circulation 2003;107: 455-60.

103. Willmann J, Lutz A, Paulmurugan R, Patel M, Chu P, Rosenberg $\mathrm{J}$, et al. Dual-targeted contrast agent for US assessment of tumor angiogenesis in vivo. Radiology 2008;248:936-44.

104. Castellani P, Borsi L, Carnemolla B, Biro A, Dorcaratto A, Viale GL, et al. Differentiation between high- and low-grade astrocytoma using a human recombinant antibody to the extra domain-B of fibronectin. Am J Pathol 2002;161:1695-700.

105. Matter CM, Schuler PK, Alessi P, Meier P, Ricci R, Zhang D, et al. Molecular imaging of atherosclerotic plaques using a human antibody against the extra-domain B of fibronectin. Circ Res 2004;95:1225-33.

106. Viti F, Tarli L, Giovannoni L, Zardi L, Neri D. Increased binding affinity and valence of recombinant antibody fragments lead to improved targeting of tumoral angiogenesis. Cancer Res 1999; 59:347-52.

107. Santimaria M, Moscatelli G, Viale G, Giovannoni L, Neri G, Viti $\mathrm{F}$, et al. Immunoscintigraphic detection of the ED-B domain of fibronectin, a marker of angiogenesis, in patients with cancer. Clin Cancer Res 2003;9:571-9.

108. Semenza GL. Targeting HIF-1 for cancer therapy. Nat Rev Cancer 2003;3:721-32.

109. Bredow S, Lewin M, Hofmann B, Marecos E, Weissleder R. Imaging of tumour neovasculature by targeting the TGF-[beta] binding receptor endoglin. Eur J Cancer 2000;36:675-81.

110. Korpanty G, Carbon J, Grayburn P, Fleming J, Brekken R. Monitoring response to anticancer therapy by targeting microbubbles to tumor vasculature. Clin Cancer Res 2007;13:323-30.

111. Pochon SP, Tardy IP, Bussat PB, Bettinger TP, Brochot JB, von Wronski MP, et al. BR55: A lipopeptide-based VEGFR2targeted ultrasound contrast agent for molecular imaging of angiogenesis. Invest Radiol 2010;45:89-95.

112. Sahoo SK, Labhasetwar V. Nanotech approaches to drug delivery and imaging. Drug Discov Today 2003;8:1112-20.
113. Sandhiya S, Dkhar SA, Surendiran A. Emerging trends of nanomedicine-An overview. Fundam Clin Pharmacol 2009;23: 263-9.

114. Newman CMH, Bettinger T. Gene therapy progress and prospects: Ultrasound for gene transfer. Gene Ther 2007;14:465-75.

115. Frinking PJA, Bouakaz A, de Jong N, Ten Cate FJ, Keating S. Effect of ultrasound on the release of micro-encapsulated drugs. Ultrasonics 1998;36:709-12.

116. Kobulnik J, Kuliszewski MA, Stewart DJ, Lindner JR, Leong-Poi H. Comparison of gene delivery techniques for therapeutic angiogenesis: Ultrasound-mediated destruction of carrier microbubbles versus direct intramuscular injection. J Am Coll Cardiol 2009;54:1735-42.

117. Suzuki JI, Ogawa M, Takayama K, Taniyama Y, Morishita R, Hirata Y, et al. Ultrasound-microbubble-mediated intercellular adhesion molecule-1 small interfering ribonucleic acid transfection attenuates neointimal formation after arterial injury in mice. J Am Coll Cardiol 2010;55:904-13.

118. Juffermans LJM, Meijering DBM, van Wamel A, Henning RH, Kooiman K, Emmer M, et al. Ultrasound and microbubble-targeted delivery of therapeutic compounds: ICIN Report Project 49: Drug and gene delivery through ultrasound and microbubbles. Neth Heart J 2009;17:82-6.

119. Ohl CD, Arora M, Ikink R, de Jong N, Versluis M, Delius M, et al. Sonoporation from jetting cavitation bubbles. Biophys $\mathbf{J}$ 2006;91:4285-95.

120. van Wamel A, Kooiman K, Harteveld M, Emmer M, ten Cate FJ, Versluis M, et al. Vibrating microbubbles poking individual cells: Drug transfer into cells via sonoporation. J Control Release 2006;112:149-55.

121. Meijering BDM, Juffermans LJM, van Wamel A, Henning RH, Zuhorn IS, Emmer M, et al. Ultrasound and microbubbletargeted delivery of macromolecules is regulated by induction of endocytosis and pore formation. Circ Res 2009;104:679-87.

122. Hellings WE, Peeters W, Moll FL, Piers SRD, van Setten J, van der Spek PJ, et al. Composition of carotid atherosclerotic plaque is associated with cardiovascular outcome. A prognostic study. Circulation 2010;121:1941-50.

123. Wu YW, Kao HL, Chen MF, Lee BC, Tseng WYI, Jeng JS, et al. Characterization of plaques using 18F-FDG PET/CT in patients with carotid atherosclerosis and correlation with matrix metalloproteinase-1. J Nucl Med 2007;48:227-33.

124. Izquierdo-Garcia D, Davies JR, Graves MJ, Rudd JHF, Gillard JH, Weissberg PL, et al. Comparison of methods for magnetic resonance-guided [18-F]fluorodeoxyglucose positron emission tomography in human carotid arteries: Reproducibility, partial volume correction, and correlation between methods. Stroke 2009;40:86-93.

125. Gessner R, Dayton P. Advances in molecular imaging with ultrasound. Mol Imaging 2010;9:117-27.

126. Cai W, Rao J, Gambhir SS, Chen X. How molecular imaging is speeding up antiangiogenic drug development. Mol Cancer Ther 2006;5:2624-33. 